\title{
All that bleeds is not infliximab-refractory ulcerative colitis
}

\author{
JK Law MD, B Salh MBChB, EM Yoshida MD
}

\begin{abstract}
JK Law, B Salh, EM Yoshida. All that bleeds is not infliximabrefractory ulcerative colitis. Can J Gastroenterol 2009;23(2):9192.

The role of biological agents in moderate to severe ulcerative colitis has been shown to be effective in the induction of clinical remission. However, the role of infliximab therapy for induction of remission in patients with fulminant colitis is debatable. A case of a hospitalized patient with a new diagnosis of severe ulcerative colitis refractory to intravenous steroids is presented. The patient was treated with infliximab and discharged with clinical remission, but subsequently presented back to hospital with a lower gastrointestinal hemorrhage.
\end{abstract}

Key Words: Infliximab, Severe colitis

\section{Une hémorragie ne découle pas nécessairement d'une colite ulcéreuse réfractaire à l'infliximab}

On a démontré l'efficacité des agents biologiques dans la colite ulcéreuse de modérée à grave pour l'induction de la rémission clinique. Toutefois, le rôle du traitement par infliximab pour l'induction de la rémission chez les patients souffrant d'une colite fulminante est controversé. On présente ici le cas d'un patient hospitalisé présentant un diagnostic récent de colite ulcéreuse grave réfractaire aux corticostéroïdes. Le patient a été traité au moyen d'infliximab et a reçu son congé une fois en rémission clinique, mais par la suite il s'est présenté de nouveau à l'hôpital pour hémorragie digestive basse.

\section{CASE PRESENTATION}

A 29-year-old Chinese man with a one-month history of frequent bloody bowel movements and abdominal pain presented for medical attention and underwent colonoscopy. A diagnosis of mild to moderate ulcerative colitis involving the entire length of the colon, with sparing of the terminal ileum, was made endoscopically and confirmed on mucosal biopsies. Initial therapy as an outpatient consisted of mesalamine at a dose of $4 \mathrm{~g} /$ day. Despite this treatment, the patient presented to the hospital 10 days later with severe abdominal pain, tachycardia and persistent bloody bowel movements in excess of five per day. Initial therapy on admission consisted of intravenous steroids. On day 3 of admission, there was no evidence of clinical improvement. A flexible sigmoidoscopy was performed at that time, revealing severe disease (Figure 1) and no evidence of infection. Medical and surgical options were discussed with the patient and the patient declined rescue cyclosporine therapy and surgical management. Infliximab (Remicade, Schering-Plough, Canada) (1) was initiated after 10 days of intravenous steroids. Within two days, the abdominal discomfort and bowel frequency significantly improved, allowing for discharge from hospital.

Five days following discharge, the patient again presented to the emergency department with a three-day history of recurrent blood per rectum infrequently associated with bowel movements. On presentation, the patient was tachycardic and hypotensive but did not have any abdominal discomfort. Presenting laboratory results revealed a hemoglobin of $48 \mathrm{~g} / \mathrm{L}$ (normal $135 \mathrm{~g} / \mathrm{L}$ to $170 \mathrm{~g} / \mathrm{L}$ ), which was a significant drop of $96 \mathrm{~g} / \mathrm{L}$ from the level measured at the time of discharge five days previously. An urgent sigmoidoscopy was performed and a spurting visible vessel was visualized in the rectum that was treated with epinephrine injection and argon plasma coagulation therapy (Figure 2). The mucosa on sigmoidoscopy appeared significantly healed compared with the sigmoidoscopy performed just before the first infliximab dose and was now consistent with mild disease. The patient was transfused with four units of packed red blood cells and observed for three days, during which, no further bleeding occurred. The patient admitted to straining with defecation before the onset of bleeding. The bleeding lesion was most likely secondary to the physical trauma of straining, a mechanism analogous to that of the solitary rectal ulcer syndrome (2).

\section{DISCUSSION}

Infliximab, a monoclonal antibody to tumour necrosis factoralpha, has been shown to be effective in inducing clinical and endoscopic remission in patients with moderate to severe ulcerative colitis not responsive to conventional therapy (3-5). In the medical management of steroid-refractory ulcerative colitis, the need for colectomy is an indication of failure with either cyclosporine or infliximab (6). However, in definitions set out by the Oxford group (7), refractoriness to medical therapy was defined as continued rectal bleeding and stool frequency of more than three times per day. Clinically, given the severity of the colitis on sigmoidoscopy before infliximab commencement and the temporal proximity to initiation of infliximab therapy, the present patient would have been labelled refractory and considered for total colectomy if an emergent sigmoidoscopy was not performed. Our experience underscores the importance of endoscopy in the confirmation of ulcerative colitis activity and response to therapy when evaluating the patient presenting with rectal bleeding after treatment with infliximab. We speculate that the fragile inflamed rectal mucosa predisposed this patient to a mechanical injury from straining. Needless to say, patients similar to the one presented herein should be advised to avoid undue straining with defecation. The patient is now one year out from his diagnosis and maintained on regular infliximab infusions.

\footnotetext{
Division of Gastroenterology, University of British Columbia, Vancouver, British Columbia

Correspondence: Dr Joanna K Law, St Paul's Hospital, Gastroenterology Clinic, 1081 Burrard Street, Vancouver, British Columbia V6Z 1 Y6.

Telephone 604-688-6332, fax 604-689-2004, e-mail jklaw99@gmail.com

Received for publication June 17, 2008. Accepted June 18, 2008
} 


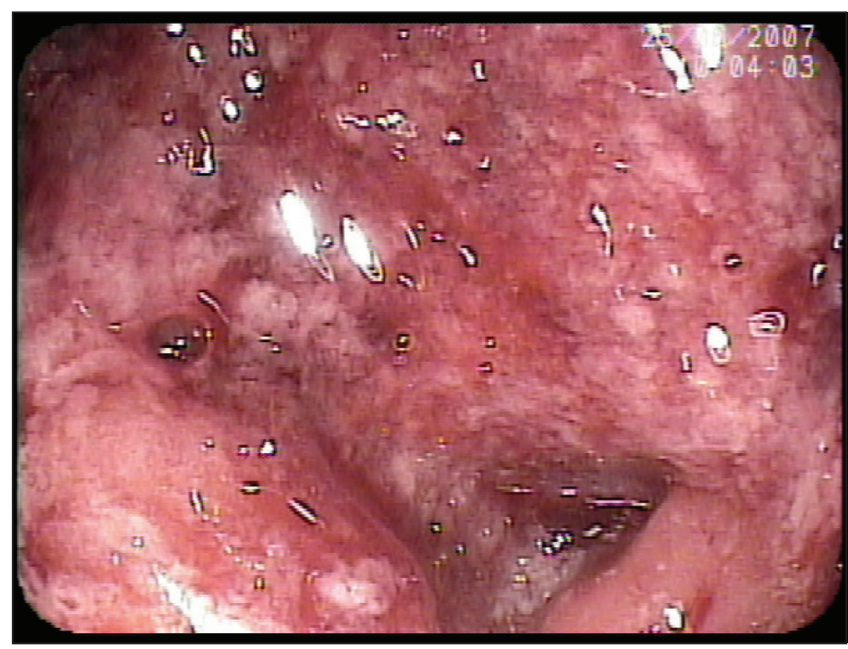

Figure 1) Flexible sigmoidoscopy revealing severe disease

\section{REFERENCES}

1. Health Flash: A Quarterly Publication: New Drugs and Indications reviewed at the March to June 2006 DEC Meetings. 2006;8:4.

2. Earnest DL, Hixson LJ. Non-specific or solitary ulcers of the colon and rectum. In: Sleisenger MH, Fordtran JS eds. Gastrointestinal Disease, 5th edn. Philadelphia: WB Saunders Company, 1993:1549-51.

3. Rutgeerts P, Sandborn WJ, Feagan BG, et al. Infliximab for induction and maintenance therapy for ulcerative colitis. N Eng J Med 2005;353:2462-76.

4. Jarnerot G, Hertervig E, Friis-Liby I, et al. Infliximab as rescue therapy in severe to moderately severe ulcerative colitis:

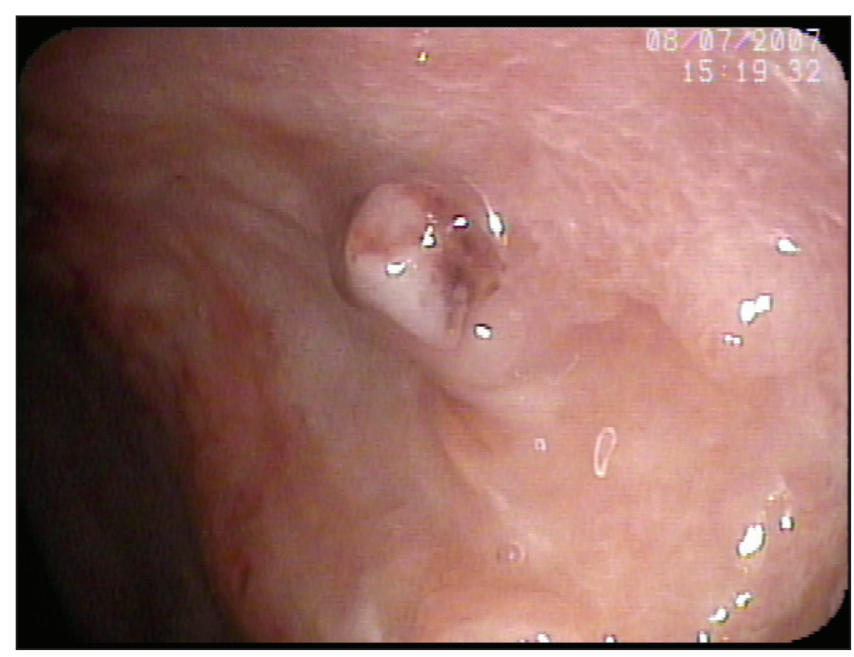

Figure 2) Repeat endoscopy revealing actively bleeding visible vessel

A randomized, placebo-controlled study. Gastroenterology 2005; 128:1805-11

5. Sands BE, Tremaine WJ, Sandborn WJ, et al. Infliximab in the treatment of severe, steroid-refractory ulcerative colitis: A pilot study. Inflamm Bowel Dis 2001;7:83-8.

6. Jakobivts SL, Jewell DP, Travis SPL. Infliximab for the treatment of ulcerative colitis: Outcomes in Oxford from 2000 to 2006. Aliment Pharmacol Therap 2007;25:1055-60.

7. Truelove SC, Jewell DP. Intensive intravenous regimen for severe attacks of ulcerative colitis. Lancet 1974;1:1067-70. 


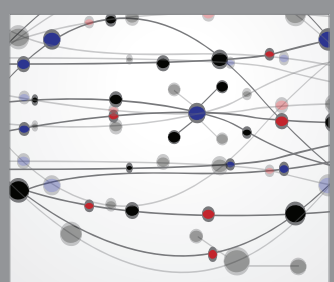

The Scientific World Journal
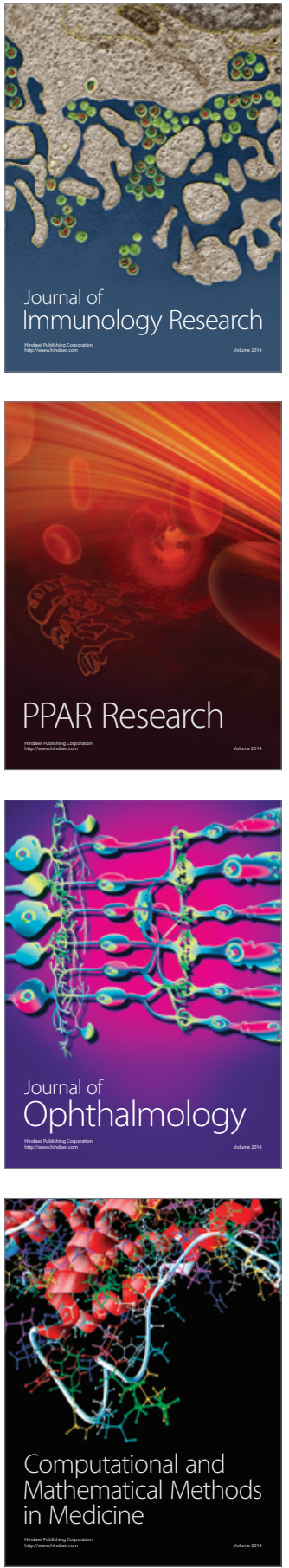

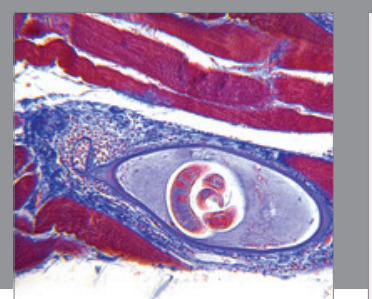

Gastroenterology Research and Practice

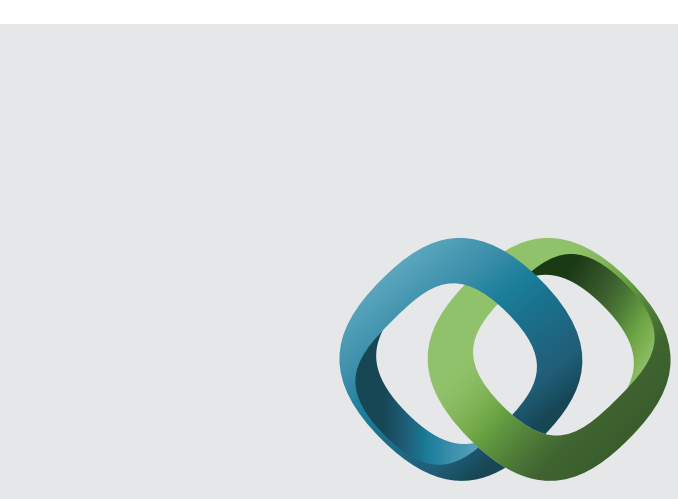

\section{Hindawi}

Submit your manuscripts at

http://www.hindawi.com
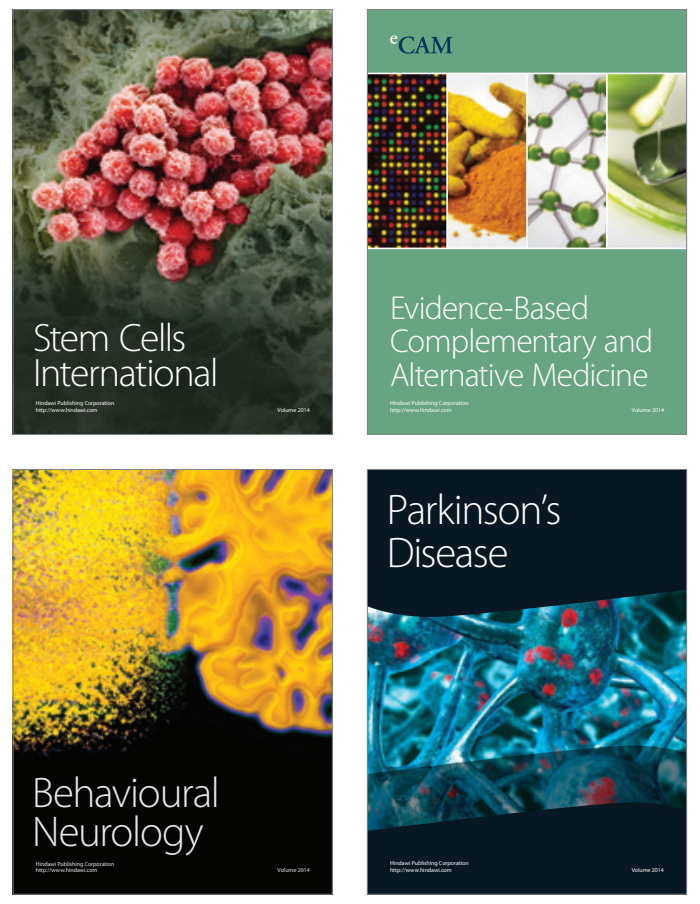
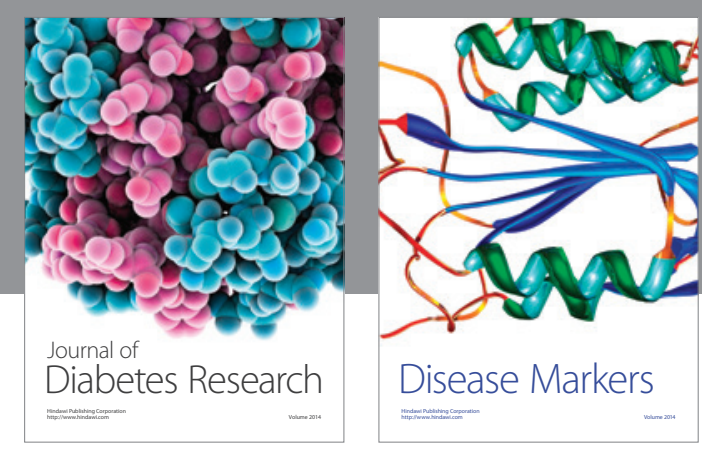

Disease Markers
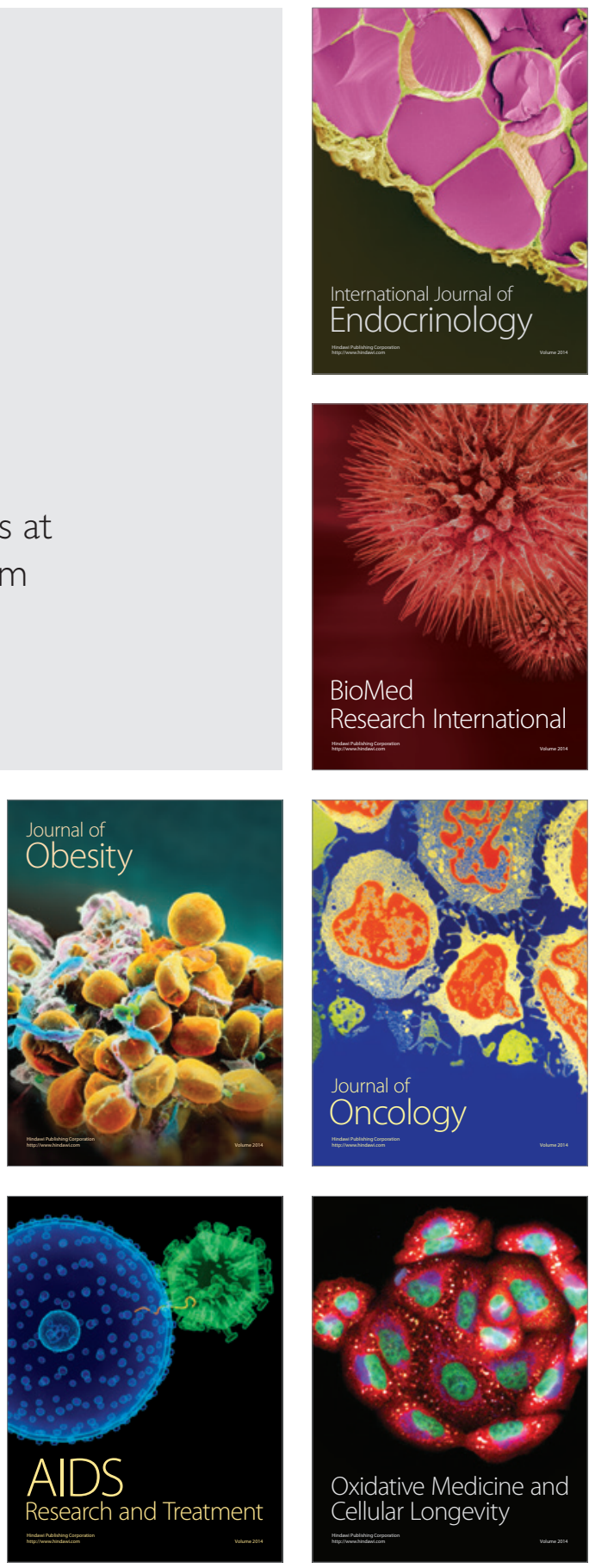